\title{
Comparison of Pharmacokinetics of Dapsone in Male Sprague Dawley Rats Following Retro Orbital, Jugular Vein and Saphenous Vein Blood Sampling
}

\author{
Subrahmanyam Vangala ${ }^{1 *}$, Rao Mukkavilli' ${ }^{2}$, Gajanan Jadhav ${ }^{1}$, Prasanna Kumar ${ }^{1}$, Praveen $\mathbf{S}^{1}$ \\ and Ajit Gadekar ${ }^{1}$ \\ ${ }^{1}$ Advinus Therapeutics Limited, Karnataka, India \\ ${ }^{2}$ Research Scholar, Manipal University, Manipal, Karnataka, India
}

Received: January 11, 2015, Accepted: April 13, 2015, Published: April 27, 2015

*Corresponding author: Subrahmanyam Vangala, Advinus Therapeutics Limited, Plot numbers 21, 22Phase 2, Peenya Industrial Area, Bengaluru560058, Karnataka, India, Tel: +91-080-2839-4959; E-mail: mani.vangala@advinus.com

\begin{abstract}
Pharmacokinetic (PK) studies play an important role in identifying lead compounds for further development. Typically rats are used for PK screening of New Chemical Entities (NCEs) as the compound requirements are minimal $(<10 \mathrm{mg})$, multiple blood sampling (up to 10 samples) can be performed from the same animal and in small volumes $(5-25 \mu \mathrm{L})$ for sample analysis. Blood sampling site is critical in obtaining multiple blood samples of good quality and in small volumes with minimal stress to animals. However, it is not known whether PK parameters can be influenced by sampling site. Thus, in this study, we evaluated the effect of different blood sampling sites like retro-orbital plexus, jugular vein and saphenous vein on PK parameters of Dapsone. Dapsone was administered both orally and intravenously at a dose of $12 \mathrm{mg} / \mathrm{kg}$ to a group of 4 male Sprague Dawley rats and blood samples were collected up to $24 \mathrm{~h}$. Samples were analyzed by LC/MS/MS and PK parameters were calculated. With all the sampling techniques, PK parameters like clearance, volume of distribution, half-life and bioavailability were similar. Due to the control on the blood volume withdrawn at each time point, quick sampling with minimal hemolysis and minimal animal handling stress during sampling, Jugular Vein (JV) or Saphenous Vein (SV) sampled rats can be used for PK studies. Further for saphenous sampling no pre-study preparation like cannulation is required before dosing the animals therefore sampling of rats through saphenous vein is recommended for pharmacokinetic and toxicokinetic studies. To summarize, SV sampling reduce the number of animals in different Pharmacokinetic (PK) (mouse) and Toxicokinetic (TK) (mouse and rat) studies by using serial draws, offers reduction and refinement over the othersampling techniques with minimal preparation upfront and with a potential to replace them.
\end{abstract}

Keywords: Pharmacokinetics; LC-MS/MS; Retro-orbital sampling; Jugular vein cannulation; Saphenous vein sampling

\section{Abbreviations}

AUC: Area Under the Curve; $\mathrm{C}_{\max }$ : Concentration maximum; NCEs: New Chemical Entities; IV: Intravenous; JVC: Jugular Vein Cannulation; PO: Per Oral; PK: Pharmacokinetics; SV: Saphenous Vein; LC-MS/MS: Liquid Chromatography Tandem Mass

\section{Spectrometry}

\section{Introduction}

Pharmacokinetic (PK) studies play a vital role in selecting a lead compound for further development. Rats are the preferred rodent species for assessing PK behavior of new chemical entities (NCEs).Typically during drug discovery phase limited compound availability can be a hurdle to conduct detailed and robust pharmacokinetic studies with large number of animals. In addition, using large number of animals is of ethical concern and therefore complying with 3Rs (reduce, refine and replace) is of major challenge. The recent advances in micro sampling techniques, highly sensitive LC-MS methods made it possible to conduct robust and detailed PK studies during drug discovery, with limited number of animals.

In vivo PK studies in rodents like hamster, mouse and rat remain a preferred screening strategy for selecting lead molecules for development. Typically, in PK studies, following administration of the compound, serial blood samples (usually 9-10 time points) are preferred, as they give a more robust concentration versus time profile within the same animal. These samples are analyzed for the parent or metabolite using a suitable analytical technique. The objective is to determine the rate of appearance and/or disappearance of the compound in the blood/plasma. Based on the PK and other druggable properties, the NCEs are rank ordered and decisions are made for further development of the NCE.

There are various factors which can affect the quality of PK data such as stress during animal handling [1], blood loss with serial sampling [2], feed [3,4], age and gender [5]. Another important factor to consider is blood sampling site like retroorbital puncture [6], tail vein [6], Saphenous vein [6,7], jugular vein [8-10], sublingual [11], and tail snip [12], all of which have their own inherent advantages and disadvantages. According to published literature, in a day $(24 \mathrm{~h})$, no more than $10 \%$ of total 
circulating blood volume should be withdrawn from each animal $[13,14]$. For example, from a rat weighing $250 \mathrm{~g}$ containing $\sim 16 \mathrm{~mL}$ blood, a maximum of $1.6 \mathrm{~mL}$ of blood can be withdrawn in 7 day period. Thus, only $160 \mu \mathrm{L}$ of blood can be withdrawn for each time point for a 10 time point serial blood collections and only 70-80 $\mu \mathrm{L}$ of plasma can be harvested from it. The recent advances in analytical methods permit the use of plasma sample as low as $5 \mu \mathrm{L}$ for quantitation of the analyte [15].

Of the different sampling techniques, retro-orbital puncture is the most preferred method of blood sampling but controlling blood flow to below $160 \mu \mathrm{L}$ blood withdrawn per time point is a challenge. In addition, it is recommended that blood sampling via this route is conducted under general anesthesia. However, some anesthetic agents undergo biotransformation by cytochrome P450 isozymes and inactivate CYP enzymes, thus leading to flawed PK estimations. After using anesthesia, artificial tears are recommended to offset the dryness of eyes. In addition, retro-orbital puncture may also be subjected to potential ocular complications including hematoma, corneal ulceration, keratitis, pannus formation, rupture of the eye globe, damage of the optic nerve and other intra-orbital structures and necrotic dacryoadenitis [16], of the harderian gland [17-20]. Due to these reasons, Netherlands banned retro-orbital blood sampling.

Lateral tail vein bleeding is also used very often for pharmacokinetic studies. Repeated blood sampling via tail vein, does not require anesthesia, and low sample volumes (100-150 $\mu \mathrm{L} /$ time point) can be obtained. Repeated punctures of tail vein at the same site may result in bruising, blood clots and necrosis. Since tails of the animals are used to lift the animals any damage to it induces further stress in animals. Thus, it is recommended to use different sites of the vein on the tail starting from tip of the tail to the tail base.Another frequent problem is warming of tail vein to improve blood flow and visibility of the vein. This can lead to dehydration and increasing the metabolic rate. During pharmacokinetic sampling of earlier time points, it can create problems in accurate timing of obtaining blood samples. In addition, animals also require a restrainer. It is also reported that the blood obtained from tail vein may be of poor quality and often hemolyzed with increase in stress levels as indicated by increase in blood glucose levels [21,22].Tail vein bleeding may also be conducted by amputation of tail tip. However, serial amputation resulting in a significant shortening of the tail, (i.e. $>5 \mathrm{~mm}$ ) are not acceptable. In addition, this technique is not suitable for older animals.

Another popular and often preferred method of PK blood sampling is by cathetered jugular vein. This technique requires prior surgical manipulation for implanting the catheter. Animals require general anesthesia for this procedure and conducted aseptically. After surgery, animals require $48 \mathrm{~h}$ of recovery period. Analgesics like buprenorphine with short half-life are usually given to animalsto reduce the pain from surgery [23]. However, these analgesics are extensively metabolized in liver by CYP3A4 and CYP2D6 and care should be exercised to prevent potential flawed $\mathrm{PK}$ results due to drug-drug interaction potential. It is essential that animals do not contract infection during the recovery period and that the cannula is firmly implanted without any blood clots. The advantage of using these animals is that fluid can be replenished so that blood samples can be taken without hypovolemic shock. During the course of the experiment, there is no need to handle the animal at any time point and sampling is done through a catheter.

Another technique for repeat blood sampling in rats and mice is via saphenous vein. This technique does not require anesthesia but requires animal holding. The saphenous vein is on the lateral side of the tarsal joint and easier to see when the fur is shaved and wiped with alcohol. The vein is raised by gentle pressure above the joint and the vessel is punctured using the smallest gauge needle (e.g. 25-27 g) that enables sufficiently rapid blood withdrawal without hemolysis. For small volumes $(\sim 10-15 \mu \mathrm{L})$, a simple stab leads to a drop of blood forming immediately at the puncture site and a hematocrit tube can be used to collect a standard volume. At the site of collection silicon greaseis applied to ensure that the blood sample does not spread [7]. Removal of the clot scab enables serial sampling. Thus, serial sampling with controlled blood flow is an advantage with this technique. After blood has been collected, pressure over the site is sufficient to stop further bleeding.

In this study, using dapsone as the model drug [24-27], we compared its pharmacokinetic behavior following oral and intravenous administration and blood sampling via retro-orbital plexus, jugular vein and Saphenous vein [25]. The results are discussed with regard to the sampling site and pharmacokinetic behavior of dapsone.

\section{Experimental}

\section{Chemicals and reagents}

Dapsone (catalogue \# 46158, purity 100\%), midazolam (catalogue \# M2419, purity: 99\%), ammonium formate (catalogue \# 17843, purity > 99\%) and formic acid (catalogue \# V800192, purity $>98 \%$ ), were procured from Sigma-Aldrich (Bengaluru, India). HPLC grade acetonitrile and methanol were procured from (Merck, Mumbai, India). All other reagents used in the study were of analytical reagent (AR) grade.Polyethylene (PE)10, PE-30, PE-50 and tygon tubing were purchased from Instech, Ahmedabad, India. Sterile water for preparation of formulations was procured from medical store.

\section{Animal husbandry}

All animal experiments were approved by the Institutional Animal Ethics Committee (IAEC) of Advinus Therapeutics Limited (an AAALAC accredited facility), Bengaluru and were in accordance with the Committee for the Purpose of Control and Supervision of Experiments on Animals (CPCSEA), Government of India. Male Sprague Dawley rats (8-12 weeks) weighing between 250-300 g were procured from in-house animal facility. Rats were housed individually in polypropylene cages. Temperature and humidity were recorded daily and were maintained between $22 \pm 3^{\circ} \mathrm{C}$ and $40-70 \%$, respectively, with $12 \mathrm{~h}$ light and dark cycle. All the animals were acclimatized to the experimental conditions for 5 days before dosing. Animals catheterized with jugular vein 
were given a recovery period of $48 \mathrm{~h}$ before dosing. Ssniff ${ }^{\circledR}$ rodent pellet diet (SsniffSpezialdiäten GmbH, Germany) and water (UV treated and purified through water filter) were provided $a d$ libitum. Animals in the oral group were fasted overnight and food was provided $4 \mathrm{~h}$ post dose.

\section{Cannula construction for jugular vein catheterization}

Hard cannula (PE-50, $13 \mathrm{~cm}$ ) and a microbore tygon tube of $2 \mathrm{~mm}$ were linked with a bio-adhesive and allowed to dry for $15 \mathrm{~min}$. Polyurethane soft cannula of approximately $1.5 \mathrm{~cm}$ was cut and allowed to dilate by dipping in xylene, then inserted into PE-50 cannula (approx. 4 to $5 \mathrm{~mm}$ ) and ensured both are tightly bound. The cannula was washed with water and sterilized it by placing in $70 \%$ ethanol overnight. The cannula was cut to have 3 $\mathrm{cm}$ length from the insertion end to bead of the cannula.

\section{Jugular vein cannulation}

Rats were anesthetized by using ketamine and xylazine mixture (90:10, IP, Dose volume: $2 \mathrm{~mL} / \mathrm{kg}$ ). A $2 \mathrm{~cm}$ ventral cervical skin incision was made right of the midline. Underlying salivary and lymphatic tissues were separated by means of blunt dissection to visualize the right common jugular vein. Jugular vein was then isolated from surrounding tissues and pair of thread was passed below the blood vessel. Tunnel was made with help of trochar to exteriorize the cannula towards neck. The jugular vein catheter consisted of polyethylene (PE-30) as catheter tippet and polyurethane $(3 \mathrm{Fr}$ ) cannulas catheter body. The exteriorized part was made secure in place with the 3-0 life line sterile thread. Skin incision was closed and the exteriorized cannula was filled with lock solution (100 IU/mL of heparinized saline). Animals were then kept on a thermo pad maintained at $37^{\circ} \mathrm{C}$ to recover. With this procedure, we achieved patency of $100 \%$ and were maintained for at least $72 \mathrm{~h}$ without any blockages.

\section{Study design}

Animals in each group were dosed as per the study design presented in table 1 . All the animals were weighed before dose administration and were used for calculation of volume required for each animal. Dose formulations were prepared on the day of dosing. Formulation recipe consisted of $5 \% \mathrm{v} / \mathrm{v}$ ethanol and $25 \%$ PEG 300and sterile waterfor injection q.s., for both intravenous and oral dose administration.Before dosing, an aliquot (100 $\mu \mathrm{L}$ ) of formulations were collected in $100 \mu \mathrm{L}$ of acetonitrile in triplicate. Formulations for each group were analyzed by LC/MS/ MS and were found to be within $\pm 15 \%$ of nominal concentration. Intravenous dosing for all the group animals was performed through tail vein and oral dosing was performed using gavage needle.

\section{Sampling}

Blood samples were collected at pre-dose, 0.083 (only IV), $0.25,0.5,1,2,4,8$ and $24 \mathrm{~h}$ in microfuge tubes containing $\mathrm{K}_{2}$ EDTA $(20 \mu \mathrm{L} / \mathrm{mL}$ of blood, $200 \mathrm{mM})$ as anticoagulant. For retro-orbital sampling, animals were anesthetized with isoflurane. In jugular vein catheterized rats, after each sampling, equal volume of heparinized saline $(10 \mathrm{IU} / \mathrm{mL})$ was injected. For collection of blood in saphenous vein animals, the sampling area was shaved and applied with silicon grease. Plasma was harvested from blood by centrifugation of samples at $2500 \mathrm{~g}$ for $10 \mathrm{~min}$ at $4{ }^{\circ} \mathrm{C}$ and stored below $-60^{\circ} \mathrm{C}$ until bioanalysis.

\section{Bioanalysis}

All samples were processed using protein precipitation method and analyzed using LC-MS/MS (LC System, Shimadzu; API-4000, AB SCIEX) method employing positive ionization ESI mode. The chromatographic separation was carried out on a C-8 reverse phase column (Kromasil, 50 x $4.6 \mathrm{~mm}, 5$ micron; Phenomenex, Hyderabad, India). The mobile phase consisted of acetonitrile:ammonium formate $(60: 40)$ containing $0.05 \%$ formic acid at a flow rate of $0.5 \mathrm{~mL} / \mathrm{min}$. The column oven was maintained at $30^{\circ} \mathrm{C}$. The analyte (dapsone) and midazolam (internal standard) samples were monitored using multiple reaction monitoring (MRM) transitions of 249.20/156.10 m/z and $326.10 / 291.10 \mathrm{~m} / \mathrm{z}$, respectively. The optimized LC-MS/ MS parameters had declustering potential of $80 \mathrm{~V}$, entrance potential of $10 \mathrm{~V}$, collision energy for MS/MS was $20 \mathrm{eV}$, collision gas was $10 \mathrm{Psi}$, curtain gas was $30 \mathrm{Psi}$, ion gas 1 was $30 \mathrm{Psi}$, ion gas 2 was $60 \mathrm{Psi}$, ion spray voltage was $3000 \mathrm{~V}$ and temperature was $500^{\circ} \mathrm{C}$. All samples collected from the jugular vein, retroorbital and saphenous vein were diluted 5-10 fold. An aliquot of plasma $(50 \mu \mathrm{L})$ was processed by addition of $200 \mu \mathrm{L}$ of internal standard containing midazolam $(25 \mathrm{ng} / \mathrm{mL})$. All the samples were vortex mixed for $5 \mathrm{~min}$ and centrifuged at $2500 \mathrm{~g}$ for 5 min. The supernatant was transferred to the LC-MS/MS vials and analyzed. The method employed a calibration curve range of 0.48 to $5970 \mathrm{ng} / \mathrm{mL}$ for dapsone with at least 8 non-zero calibration standards with acceptance criteria of $\pm 15 \%$ at all concentrations, except $\pm 20 \%$ at LLOQinterspersed with quality control samples consisting of LQC, M1QC, MQC and HQC. Dilution quality control samples were also assessed to ensure the dilution integrity.

\section{Pharmacokinetic analysis}

Pharmacokinetic parameters were calculated using noncompartmental analysis tool of validated Phoenix WinNonlin ${ }^{\circledR}$ software (Version 6.3). The area under the concentration time curve $\left(\mathrm{AUC}_{\text {last }}\right.$ and $\left.\mathrm{AUC}_{\text {inf }}\right)$ was calculated by linear trapezoidal rule. Peak plasma concentration $\left(\mathrm{C}_{\max }\right)$ and time for the peak plasma concentration $\left(\mathrm{T}_{\max }\right)$ were observed values. The $\mathrm{C}_{0}$ was estimated following intravenous bolus dose administration by back-extrapolating the first two concentration values. The clearance (CL) and volume of distribution at steady state $\left(\mathrm{V}_{\mathrm{ss}}\right.$ ) following intravenous administration were predicted values. The elimination rate constant value $(\mathrm{k})$ was calculated by linear regression of the log-linear terminal phase of the concentrationtime profile using at least 3 declining concentrations in terminal phase with a correlation coefficient of $>0.8$. The terminal halflife value $\left(\mathrm{T}_{1 / 2}\right)$ was calculated using the equation $0.693 / \mathrm{k}$. The absolute bioavailability was calculated using dose normalized $\mathrm{AUC}_{\text {inf }}$ of oral to that of intravenous.

\section{Statistical analysis}

Exposure $\left(\mathrm{C}_{\max }\right.$ and $\left.\mathrm{AUC}_{\mathrm{inf}}\right)$ between different groups for 
IV and PO dose administration were compared for statistical significance using a one-way Analysis of Variance (ANOVA) with Tukey's multiple comparisons set. A P value of less than 0.05 was considered significant. The statistical analysis was performed using GraphPad Prism software (5.2).

\section{Results}

A summary of different sampling techniques used for pharmacokinetic and toxicokinetic studies are presented in table 2. Of the techniques used, we choose the three most widely used sampling techniques to assess the differences in PK parameters using IV and PO route of administration. All oral group rats were dosed through gavage and intravenous animals received the dose through tail vein. The mean pharmacokinetic parameters following single intravenous and oral dose administration of dapsone using different sampling techniques are summarized in table 3.

Following intravenous dose administration of dapsone, the clearance was lower in jugular vein group $(3.72 \mathrm{~mL} / \mathrm{min} /$ $\mathrm{kg}$ ), followed by retro-orbital group (4.31 $\mathrm{mL} / \mathrm{min} / \mathrm{kg}$ ) and saphenous vein group $(5.09 \mathrm{~mL} / \mathrm{min} / \mathrm{kg})$. Overall clearance of dapsone was low in Sprague Dawley rat, less than $10 \%$ of liver blood flow of $55 \mathrm{~mL} / \mathrm{min} / \mathrm{kg}$. The plasma concentrations following intravenous administration declined bi-exponentially with a rapid distribution phase followed by slow elimination phase. Volume of distribution was 2-fold the total body water of $0.7 \mathrm{~L} / \mathrm{kg}$ confirming that the compound is not highly distributed to the tissues or partitioning into the red blood cells. Dapsone showed high half-life varying between $4.33 \mathrm{~h}$ to $5.79 \mathrm{~h}$ between groups.
Following oral administration, dapsone absorbed rapidly with $\mathrm{T}_{\max }$ values ranging from $0.25 \mathrm{~h}$ to $4 \mathrm{~h}$. The corresponding $\mathrm{C}_{\max }$ values were $4600 \mathrm{ng} / \mathrm{mL}$ for retro-orbital group, $5540 \mathrm{ng} /$ $\mathrm{mL}$ for jugular vein group and $5330 \mathrm{ng} / \mathrm{mL}$ for saphenous vein group. The area under the curve $\left(\mathrm{AUC}_{\mathrm{inf}}\right.$ ) was lower at $38600 \mathrm{ng} /$ $\mathrm{mL}$ for retro-orbital group compared to $45400 \mathrm{ng} / \mathrm{mL}$ for jugular veinand, $51700 \mathrm{ng} / \mathrm{mL}$ for saphenous vein sampling group. The absolute bioavailability of dapsone in retro-orbital sampling, jugular vein sampling and saphenous vein sampling groups was $83 \%, 84 \%$ and $100 \%$, respectively. The exposures obtained in retro-orbital sampling and jugular vein sampling are in agreement with the results published by Helton et al.[24]. Mean plasma concentration-time data following intravenous and oral dosing for retro-orbital plexus sampling, jugular vein sampling and saphenous vein sampling are presented in tables 4 to 9 and the corresponding intravenous and oral profiles are shown in figure 1 and 2, respectively.

The exposures $\left(\mathrm{C}_{\max }\right.$ and $\left.A U C_{\text {last }}\right)$ following intravenous and oral administration of dapsone in all the groups were similar and were not statistically significant ( $P$ value $>0.05$ ).

\section{Discussion}

Rats have traditionally been used as a laboratory animal in virtually every area of biomedical research since 1856 including the ADME and PK studies. It has been reported that in rat, certain parameters like plasma glucose, blood coagulation parameters, corticosterone levels, renin activity, serum hormone levels, serum enzyme activities and drug binding to plasma proteins may vary depending on the site and method of blood sampling, the extent of rat handling, acclimatization time and the presence of

Table 1: Study Design for Pharmacokinetic Study.

\begin{tabular}{|c|c|c|c|c|c|}
\hline Sampling technique & Route of administration & $\begin{array}{c}\text { Number of animals per } \\
\text { group }\end{array}$ & $\begin{array}{c}\text { Dose } \\
\text { (mg/kg) }\end{array}$ & $\begin{array}{c}\text { Dose volume } \\
\text { (mL/kg) }\end{array}$ & $\begin{array}{c}\text { Formulation strength } \\
\text { (mg/mL) }\end{array}$ \\
\hline \multirow{2}{*}{ Retro orbital plexus } & IV & 4 & & \\
\cline { 2 - 4 } & PO & 4 & \multirow{2}{*}{12} & \\
\hline \multirow{2}{*}{ Jugular vein } & IV & 4 & & \\
\cline { 2 - 4 } & PO & 4 & & \\
\hline
\end{tabular}

IV: intravenous dosing through tail vein, PO: oral gavage needle

Table 2: Different Sampling Techniques.

\begin{tabular}{|c|c|c|c|c|c|c|}
\hline Route of sampling & $\begin{array}{c}\text { Volume for } \\
\text { sampling }\end{array}$ & $\begin{array}{c}\text { Repeated } \\
\text { sampling }\end{array}$ & $\begin{array}{c}\text { Anesthesia } \\
\text { required }\end{array}$ & $\begin{array}{c}\text { Speed and efficiency of } \\
\text { sampling }\end{array}$ & Sample quality & Sampling stress \\
\hline Retro-orbital & M-L & Yes & Yes & Slow and need more time & Good & Yes \\
\hline Jugular vein & L & Very easy & No & Fast and timely & Excellent & No \\
\hline Saphenous vein & S-M & Yes & No & Fast and timely & Good & Very little \\
\hline Tail vein & S-M & Yes & No & Fast and timely & Good & Yes \\
\hline Tail artery & M-L & Yes & No & Fast and timely & Excellent & Yes \\
\hline Tail clip & S & Yes & No & Fast and timely & Poor & Yes \\
\hline
\end{tabular}

Adapted from reference: http://oacu.od.nih.gov/ARAC/documents/Rodent_Bleeding.pdf;

$\mathrm{S}=$ small, $\mathrm{M}=$ medium, $\mathrm{L}=$ large 
Table 3: Pharmacokinetic Parameters of Dapsone Following Intravenous and Oral Dose Administration.

\begin{tabular}{|c|c|c|c|c|c|c|c|c|c|}
\hline $\begin{array}{c}\text { Group / } \\
\text { Sampling Site }\end{array}$ & Route & $\begin{array}{l}T_{\max }^{a} \\
\text { (h) }\end{array}$ & $\begin{array}{l}\mathrm{C}_{\mathrm{o}} / \mathrm{C}_{\max }{ }^{\mathrm{S}} \\
\text { (ng/mL) }\end{array}$ & $\begin{array}{c}\mathrm{AUC}_{\text {last }} \\
\text { (ng.h/mL) }\end{array}$ & $\begin{array}{c}\mathrm{AUC}_{\text {inf }}{ }^{\mathrm{s}} \\
\text { (ng.h/mL) }\end{array}$ & $\begin{array}{c}\mathrm{CL} \\
(\mathrm{mL} / \mathrm{min} / \mathrm{kg})\end{array}$ & $\begin{array}{c}\text { Vss } \\
\text { (L/kg) }\end{array}$ & $\begin{array}{l}T_{1 / 2} \\
\text { (h) }\end{array}$ & $F^{b}$ \\
\hline \multirow{2}{*}{$\begin{array}{c}\text { I } \\
\text { Retro orbital }\end{array}$} & IV & NA & $12100 \pm 1640$ & $45700 \pm 2530$ & $46500 \pm 2390$ & $4.31 \pm 0.22$ & $1.35 \pm 0.12$ & $\begin{array}{c}4.33 \pm \\
0.17\end{array}$ & \multirow{2}{*}{83} \\
\hline & PO & $\begin{array}{c}0.75 \\
(0.25-1.0)\end{array}$ & $4600 \pm 385$ & $37000 \pm 2050$ & $38600 \pm 627$ & NA & NA & NA & \\
\hline \multirow{2}{*}{$\begin{array}{c}\text { II } \\
\text { Jugular vein }\end{array}$} & IV & NA & $13400 \pm 1150$ & $51700 \pm 4700$ & $54300 \pm 5410$ & $3.72 \pm 0.40$ & $1.50 \pm 0.16$ & $\begin{array}{c}5.79 \pm \\
0.97\end{array}$ & \multirow{2}{*}{84} \\
\hline & PO & $\begin{array}{c}1.0 \\
(0.5-1.0)\end{array}$ & $5540 \pm 1290$ & $42900 \pm 3220$ & $45400 \pm 4390$ & NA & NA & NA & \\
\hline \multirow{2}{*}{$\begin{array}{c}\text { III } \\
\text { Saphenous vein }\end{array}$} & IV & NA & $10700 \pm 1880$ & $38400 \pm 2360$ & $39400 \pm 2330$ & $5.09 \pm 0.29$ & $1.64 \pm 0.19$ & $\begin{array}{c}4.94 \pm \\
0.49\end{array}$ & \multirow{2}{*}{$\sim 100$} \\
\hline & PO & $\begin{array}{c}2.0 \\
(0.5-4)\end{array}$ & $5330 \pm 1360$ & $49800 \pm 11600$ & $51700 \pm 12200$ & NA & NA & NA & \\
\hline
\end{tabular}

${ }^{\mathrm{a}} \mathrm{T}_{\max }$ reported as median (min-max); ${ }^{\mathrm{b}} \mathrm{AUC}_{\text {inf }}$ and nominal doses are used for bioavailability calculation; NA: not applicable; ${ }^{\$} \mathrm{C}_{\max }$ and AUC ${ }_{\text {inf }}$ of IV and PO groups by all sampling routes found to be statistically insignificant, $\mathrm{p}>0.05$

Table 4: Concentration-time profile of dapsone $(12 \mathrm{mg} / \mathrm{kg})$ following tail vein dosing and retro-orbital sampling.

\begin{tabular}{|c|c|c|c|c|c|c|c|}
\hline \multirow{2}{*}{$\begin{array}{c}\text { Time point } \\
\text { (h) }\end{array}$} & \multicolumn{7}{|c|}{ Plasma concentration (ng/mL } \\
\hline 0.083 & Rat 71 & Rat 72 & Rat 73 & Rat 74 & Mean & SD & \%CV \\
\hline 0.25 & 11520 & 10892 & 10210 & 12446 & 11267 & 951 & 8 \\
\hline 0.5 & 9830 & 9572 & 10025 & 9387 & 9704 & 281 & 3 \\
\hline 1 & 8533 & 7447 & 8918 & 8920 & 8454 & 696 & 8 \\
\hline 2 & 6934 & 7085 & 7387 & 7187 & 7148 & 190 & 3 \\
\hline 4 & 4862 & 5854 & 4899 & 5154 & 5192 & 460 & 9 \\
\hline 8 & 2590 & 2561 & 2505 & 748 & 2101 & 902 & 43 \\
\hline 24 & 1534 & 1987 & 1768 & 1964 & 1813 & 211 & 12 \\
\hline & 124 & 104 & 105 & 163 & 124 & 28 & 22 \\
\hline
\end{tabular}

Table 5: Concentration-time profile of dapsone $(12 \mathrm{mg} / \mathrm{kg})$ following oral dosing and retro-orbital sampling.

\begin{tabular}{|c|c|c|c|c|c|c|c|}
\hline \multirow{2}{*}{$\begin{array}{c}\text { Time point } \\
\text { (h) }\end{array}$} & \multicolumn{7}{|c|}{ Plasma concentration (ng/mL) } \\
\cline { 2 - 8 } & Rat 75 & Rat 76 & Rat 77 & Rat 78 & Mean & SD & \%CV \\
\hline 0 & 0 & 0 & 0 & 0 & 0 & 0 & NA \\
\hline 0.25 & 3600 & 4976 & 4515 & 4647 & 4434 & 589 & 13 \\
\hline 0.5 & 4063 & 4456 & 4040 & 4032 & 4148 & 206 & 5 \\
\hline 1 & 4003 & 4471 & 4667 & 4701 & 4461 & 321 & 7 \\
\hline 2 & 3123 & 3594 & 3742 & 3935 & 3598 & 346 & 10 \\
\hline 4 & 2004 & 2165 & 2241 & 2358 & 2192 & 148 & 7 \\
\hline 8 & 1690 & 1805 & 1852 & 1850 & 1799 & 76 & 4 \\
\hline 24 & 121 & 149 & 144 & 95 & 128 & 25 & 19 \\
\hline
\end{tabular}

NA: not applicable

another previously treated rat. Summary of various parameters in rat used for pharmacokinetic studies are presented in table 10 $[10,28]$.

Blood sampling is one of the most common procedure performed on laboratory animals, and yet there is still a need to refine available techniques both from a welfare point of view and because stressful blood sampling techniques may profoundly affect physiological variables. It has been reported that if animals are handled for more than $5 \mathrm{~min}$, levels of corticosterone increases. The study of compound PK in the rat is solely dependent upon procedures that allow blood sampling. Blood can be sampled from rats in number of ways, for example by puncturing the tail vein, the sublingual vein and the saphenous vein or by implanting vascular catheters. Each method has its advantages and limitations and should be considered in order to minimize the impact of these limitations on experimental results. 
Table 6: Concentration-time profile of dapsone $(12 \mathrm{mg} / \mathrm{kg})$ following tail vein dosing and jugular vein sampling.

\begin{tabular}{|c|c|c|c|c|c|c|c|}
\hline \multirow{2}{*}{$\begin{array}{c}\text { Time point } \\
\text { (h) }\end{array}$} & \multicolumn{9}{|c|}{ Plasma concentration (ng/mL) } \\
\cline { 2 - 8 } & Rat 87 & Rat 88 & Rat 89 & Rat 90 & Mean & SD & \%CV \\
\hline 0.08 & 11900 & 12215 & 12709 & 10930 & 11939 & 751 & 6 \\
\hline 0.25 & 8312 & 9769 & 10152 & 9481 & 9429 & 793 & 8 \\
\hline 0.5 & 7349 & 8138 & 8011 & 8325 & 7956 & 425 & 5 \\
\hline 1 & 5682 & 7028 & 6649 & 6823 & 6546 & 596 & 9 \\
\hline 2 & 4054 & 4980 & 4257 & 4941 & 4558 & 473 & 10 \\
\hline 4 & 3021 & 2843 & 2787 & 3636 & 3072 & 389 & 13 \\
\hline 8 & 1704 & 2205 & 2380 & 2276 & 2141 & 301 & 14 \\
\hline 24 & 234 & 436 & 204 & 287 & 290 & 103 & 35 \\
\hline
\end{tabular}

Table 7: Concentration-time profile of dapsone $(12 \mathrm{mg} / \mathrm{kg})$ following oral dosing and jugular vein sampling.

\begin{tabular}{|c|c|c|c|c|c|c|c|}
\hline \multirow{2}{*}{$\begin{array}{c}\text { Time point } \\
\text { (h) }\end{array}$} & \multicolumn{7}{|c|}{ Plasma concentration (ng/mL) } \\
\cline { 2 - 8 } & Rat 91 & Rat 92 & Rat 93 & Rat 94 & Mean & SD & \%CV \\
\hline 0 & 0 & 0 & 0 & 0 & 2214 & 2263 & 953 \\
\hline 0.25 & 1276 & 3559 & 2005 & 3860 & 4364 & 1521 & 35 \\
\hline 0.5 & 3607 & 3364 & 6625 & 6452 & 5341 & 1112 & 21 \\
\hline 1 & 5213 & 3855 & 5844 & 4429 & 3831 & 492 & 13 \\
\hline 2 & 3875 & 3226 & 3795 & 2849 & 2758 & 331 & 12 \\
\hline 4 & 3187 & 2514 & 2482 & 2119 & 2037 & 224 & 11 \\
\hline 8 & 1705 & 2136 & 2190 & 422 & 281 & 102 & 36 \\
\hline 24 & 265 & 178 & 258 & & & & \\
\hline
\end{tabular}

NA: not applicable

Table 8: Concentration-time profile of dapsone $(12 \mathrm{mg} / \mathrm{kg})$ following tail vein dosing and saphenous vein sampling.

\begin{tabular}{|c|c|c|c|c|c|c|c|}
\hline \multirow{2}{*}{$\begin{array}{c}\text { Time point } \\
\text { (h) }\end{array}$} & \multicolumn{7}{|c|}{ Plasma concentration (ng/mL) } \\
\cline { 2 - 8 } & Rat 112 & Rat 113 & Rat 114 & Rat 115 & Mean & SD & \%CV \\
\hline 0.08 & 8127 & 11171 & 9686 & 10565 & 9887 & 1322 & 13 \\
\hline 0.25 & 8885 & 9028 & 8410 & 8618 & 8735 & 275 & 3 \\
\hline 0.5 & 6419 & 9106 & 8656 & 9272 & 8363 & 1322 & 16 \\
\hline 1 & 6599 & 6471 & 3447 & 4429 & 5237 & 1553 & 30 \\
\hline 2 & 3981 & 4757 & 4398 & 4131 & 4317 & 340 & 8 \\
\hline 4 & 2257 & 2442 & 2291 & 2641 & 2408 & 175 & 7 \\
\hline 8 & 1264 & 1433 & 1335 & 1159 & 1298 & 116 & 9 \\
\hline 24 & 118 & 129 & 195 & 128 & 143 & 35 & 25 \\
\hline
\end{tabular}

Table 9: Concentration-time profile of dapsone $(12 \mathrm{mg} / \mathrm{kg})$ following oral dosing and saphenous vein sampling.

\begin{tabular}{|c|c|c|c|c|c|c|c|}
\hline \multirow{2}{*}{$\begin{array}{c}\text { Time point } \\
\text { (h) }\end{array}$} & \multicolumn{7}{|c|}{ Plasma concentration (ng/mL) } \\
\cline { 2 - 9 } & Rat 116 & Rat 117 & Rat 118 & Rat 119 & Mean & SD & \%CV \\
\hline 0 & 0 & 0 & 0 & 0 & 0 & 0 & NA \\
\hline 0.25 & 2393 & 3734 & 1417 & 1870 & 2354 & 1003 & 43 \\
\hline 0.5 & 3504 & 6538 & 1854 & 3419 & 3829 & 1959 & 51 \\
\hline 1 & 4621 & 5321 & 2055 & 4817 & 4204 & 1462 & 35 \\
\hline 2 & 5930 & 6318 & 2644 & 5468 & 5090 & 1667 & 33 \\
\hline 4 & 4027 & 5496 & 3397 & 4783 & 4426 & 911 & 21 \\
\hline 8 & 1747 & 2739 & 1795 & 2313 & 2149 & 470 & 22 \\
\hline 24 & 193 & 387 & 232 & 278 & 273 & 84 & 31 \\
\hline
\end{tabular}

NA: not applicable 

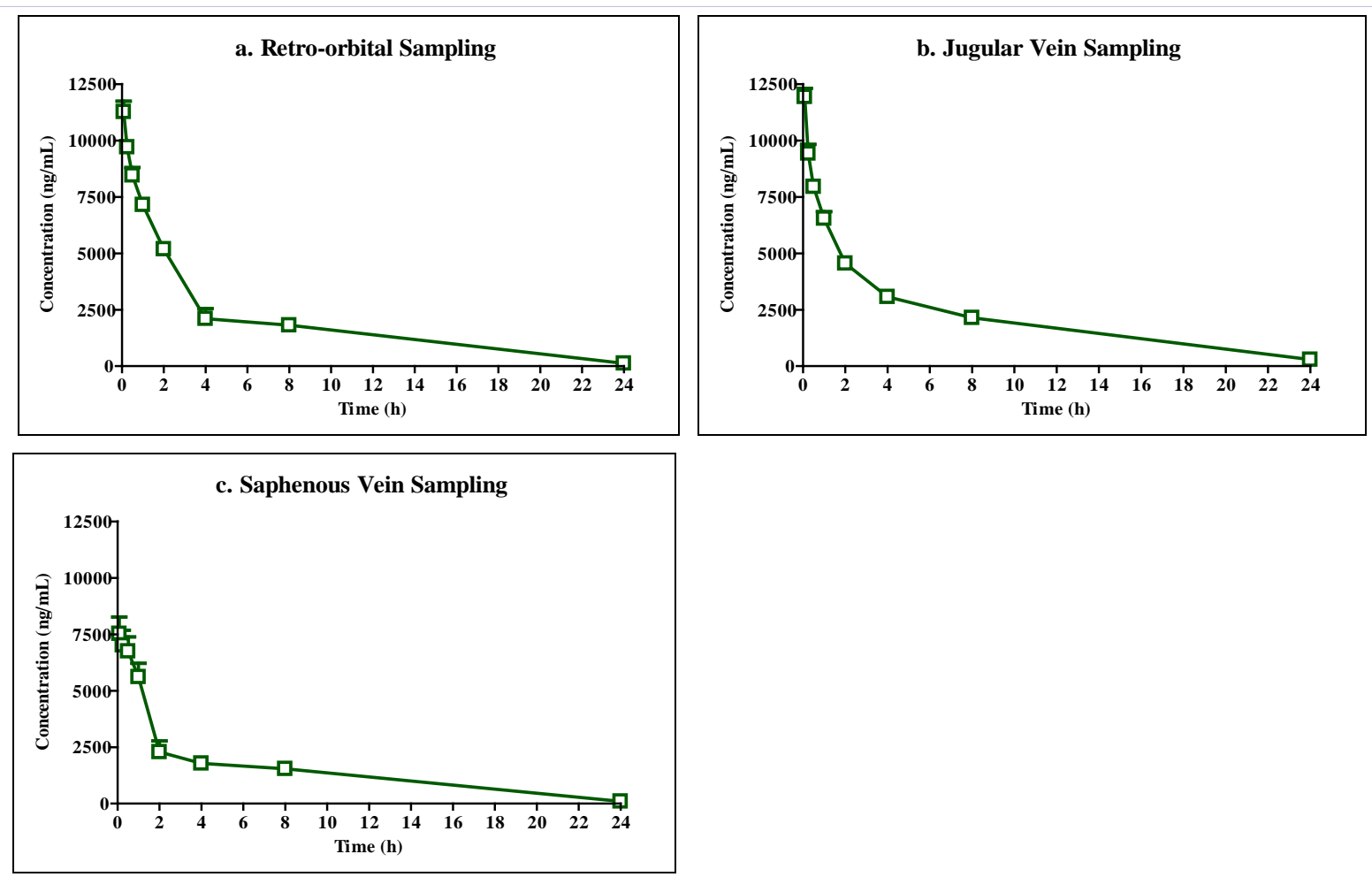

Figure 1: Concentration-Time Profile of Dapsone Following Intravenous Administration (12 mg/kg, n=3, mean + SD). a. Retro-orbital sampling, b. Jugular vein sampling, c. Saphenous vein sampling
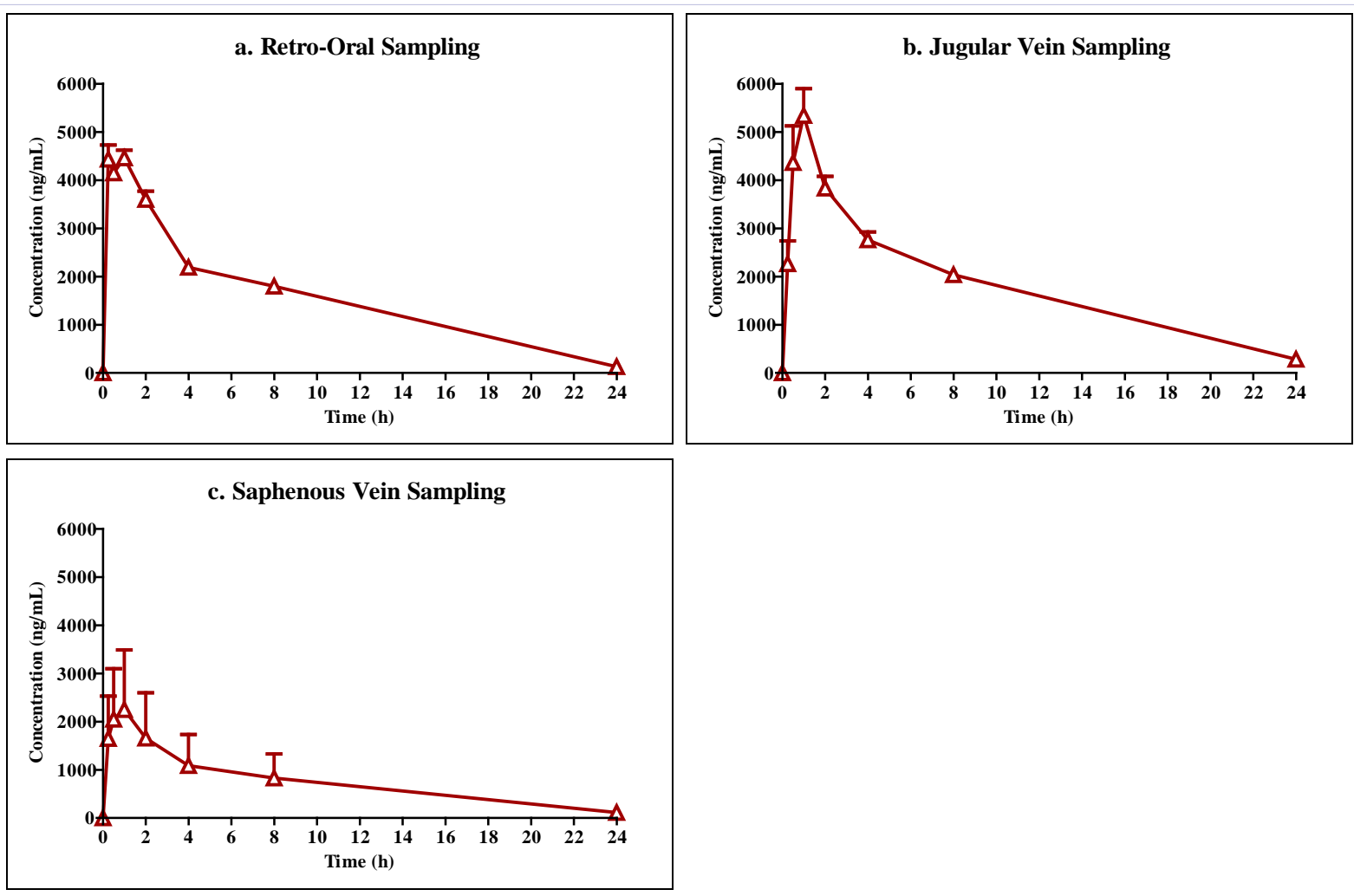

Figure 2: Concentration-Time Profile of Dapsone Following Oral Administration (12 mg/kg, n=3, mean + SD).

a. Retro-orbital sampling, b. Jugular vein sampling, c. Saphenous vein sampling 
Table 10: Summary of Various Parameters of Rats used for Pre-clinical Studies ${ }^{\text {a\&b }}$.

\begin{tabular}{|c|c|c|c|}
\hline Parameter & Range or Mean & Parameter & Range or Mean \\
\hline Weight & $250 \mathrm{~g}$ & Birth weight & $5-6 \mathrm{~g}$ \\
\hline Life span & $2.5-3 y$ & Heart rate & $330-480$ beats/min \\
\hline Surface area & $0.03-0.06 \mathrm{~cm}^{2}$ & Plasma protein & $6.2 \mathrm{~g} / 100 \mathrm{~mL}$ \\
\hline Plasma Albumin & $3.27 \mathrm{~g} / 100 \mathrm{~mL}$ & Plasma $\alpha-1$-AGP & $1.25 \mathrm{~g} / 100 \mathrm{~mL}$ \\
\hline Total oxygen consumption & $1.59 \mathrm{~mL} / \mathrm{h} / \mathrm{g}$ & Total ventilation & $0.025 \mathrm{~L} / \mathrm{min}$ \\
\hline Food consumption & $100 \mathrm{~g} / \mathrm{kg} /$ day & Stroke volume & $1.3-2.0 \mathrm{~mL} /$ beat \\
\hline Body temperature & $37^{\circ} \mathrm{C}$ & Cardiac output & $50 \mathrm{~mL} / \mathrm{min}$ \\
\hline Gestation & 21-23 days & RBC volume & $3.63 \mathrm{~mL} / \mathrm{kg}$ \\
\hline Litter size & 8-14 pups & Respiration rate & $66-114$ per $\min$ \\
\hline Total body water & $167 \mathrm{~mL}$ & Intracellular fluid & $92.8 \mathrm{~mL}$ \\
\hline Plasma volume & $7.8 \mathrm{~mL}$ & Extracellular fluid & $74.2 \mathrm{~mL}$ \\
\hline $\begin{array}{c}\text { Organ weights (g) } \\
\text { Brain } \\
\text { Liver } \\
\text { Kidney } \\
\text { Heart } \\
\text { Spleen } \\
\text { Adrenals } \\
\text { Lung }\end{array}$ & $\begin{array}{c}1.8 \\
10.0 \\
2.0 \\
1.0 \\
0.75 \\
0.05 \\
1.5\end{array}$ & $\begin{array}{c}\text { Organ volumes }(\mathrm{mL}) \\
\text { Brain } \\
\text { Liver } \\
\text { Kidney } \\
\text { Heart } \\
\text { Spleen } \\
\text { Lungs } \\
\text { Gut } \\
\text { Muscle } \\
\text { Adipose } \\
\text { Skin } \\
\text { Blood }\end{array}$ & $\begin{array}{c}1.2 \\
19.6 \\
3.7 \\
1.2 \\
1.3 \\
2.1 \\
11.3 \\
245 \\
10.0 \\
40.0 \\
13.5\end{array}$ \\
\hline $\begin{array}{c}\text { Blood flow }(\mathrm{mL} / \mathrm{min}) \\
\text { Brain } \\
\text { Liver } \\
\text { Kidney } \\
\text { Heart } \\
\text { Spleen } \\
\text { Gut } \\
\text { Muscle } \\
\text { Adipose } \\
\text { Skin } \\
\text { Hepatic artery } \\
\text { Portal vein } \\
\text { Cardiac output }\end{array}$ & $\begin{array}{c}1.3 \\
13.8 \\
9.2 \\
3.9 \\
0.63 \\
7.5 \\
7.5 \\
0.4 \\
5.8 \\
2.0 \\
9.8 \\
74.0\end{array}$ & $\begin{array}{c} \\
\text { pH (fed) } \\
\text { Stomach - Anterior } \\
\text { Stomach - Posterior } \\
\text { Small intestine } \\
\text { Beginning } \\
\text { End } \\
\text { Cecum } \\
\text { Colon } \\
\text { Feces }\end{array}$ & $\begin{array}{l}5.0 \\
3.8 \\
6.5 \\
7.1 \\
6.8 \\
6.6 \\
6.9\end{array}$ \\
\hline $\begin{array}{l}\text { Urine flow } \\
\text { GFR }\end{array}$ & $\begin{array}{l}50.0 \mathrm{~mL} / \text { day } \\
1.31 \mathrm{~mL} / \mathrm{min}\end{array}$ & Bile flow & $22.5 \mathrm{~mL} /$ day \\
\hline $\begin{array}{c}\beta \text { glucuronidase activity } \\
\text { (nmol substrate } / \mathrm{h} / \mathrm{g} \text { contents) }\end{array}$ & $\begin{array}{c}\text { Proximal small intestine - } 304 \\
\text { Distal small intestine - } 1341\end{array}$ & Transit time in small intestine & $88 \mathrm{~min}$ \\
\hline
\end{tabular}

${ }^{\mathrm{a}}$ Cocchetto et al. [10], ${ }^{\mathrm{b}}$ Davies et al. [28]

There are various published reports available where authors have tried to study the impact of site of blood sampling on animal health and compound PK. van Herck et al. [17] studied the influence of orbital sinus blood sampling by different technicians on clinical signs in rats and found that experienced animal technicians were able to perform the sampling without causing a statistically significant increase in alterations in punctured orbits. However, the less experienced animal technicians caused severe abnormalities in orbital sinus of rat. The use of either a pasteur pipette or a hematocrit capillary did not produce different results. Neither did puncturing the lateral vs the medial canthus of the orbit. They also reported that by not applying chloramphenicol eye ointment in the conjunctival sac after puncture, the number of abnormalities in ocular discharge and corneal alterations in the punctured orbits were significantly decreased. No statistically significant association was found between the eye position, 
ocular discharge, corneal alterations or intra-ocular alterations and the factor number of punctures per orbit.

Orbital sinus blood sampling is a technique used frequently in rats, but it is controversial, particularly due to the ethical and emotional nature attached to it. The BVA/FRAME/RSPCA/ UFAW joint working group had stated that orbital puncture is acceptable only as a terminal procedure while the animal is under anesthesia. The behavior of rats after orbital sinus blood sampling under light diethyl ether anesthesia, as performed by a skilled animal technician in the medial canthus of the orbit, was studied previously in an open field, and telemetrically as diurnal locomotor activity and eating pattern. In those studies, the behavior of punctured rats did not differ from that of those treated with only diethyl ether. The clinical conditions of rats after a singular orbital puncture in the medial canthus of the orbit by an experienced animal technician showed no alterations, apart from a possibly higher incidence of enophthalmia in the punctured eyes. vanHerck et al. [19] subsequently reported histological changes in the orbital region in rats after retro-orbital puncture. These included haemorrhages and inflammatory reactions in the puncture track, retro-orbital periosteum, eye muscles and Harderian gland.

There are reports that sampling method can influence clinical pathology parameters and renal functional parameters. vanHerck et al.[6] studied the effect of retro orbital, saphenous and tail vein bleeding on the behavior and blood parameters of rat. They concluded that the induction of diethyl-ether anesthesia before orbital puncture caused significantly more visible distress than did either the induction of $\mathrm{O}_{2}-\mathrm{N}_{2} \mathrm{O}$ halothane anesthesia needed for tail vein puncture or manual fixation combined with saphenous vein puncture. The three blood sampling techniques had no differential effects on the behaviors of grooming, locomotion and inactivity. Of the three methods, orbital puncture appeared to be the fastest technique. It produced the lowest plasma potassium and highest sodium levels, possibly indicating that is caused by lesser erythrocyte damage. The acid-base equilibrium of the blood samples indicated that saphenous and tail vein puncture might have induced a slight alkalosis that might be stress related. Hui et al. [26] studied the effect of tail vein, femoral artery cannula and retro orbital sinus bleeding techniques on the pharmacokinetics of six marketed drugs. They recommended tail-bleeding technique and cannulation techniques for pharmacology, toxicology exposure and PK studies, particularly in early discovery work. They concluded that retro-orbital bleeding was controversial and no longer considered a humane method.

For jugular vein sampling, cannulation is performed which typically takes $10 \mathrm{~min}$ for an experienced surgeon and is conducted under aseptic condition. The surgicals are autoclaved, sterile gloves are used and after surgery povidone and nesoprine are applied to further prevent infection. After any type of invasive surgery, it is also mandatory to administer analgesics as per the Guide for the Care and Use of Animals. Most widely used analgesic is buprenorphine (which is a controlled substance) and administered at a dose of $0.05 \mathrm{mg} / \mathrm{kg}$ through subcutaneous route. Administering buprenorphine although relives pain is associated with side effects like respiratory depression and nausea. In addition, the most critical effect of buprenorphine is on the neural function in the central nervous system leading to consequent changes in behavior. Although buprenorphine clears within $4 \mathrm{~h}$ from the systemic circulation in rats, its effects on neural function are long term and there are studies showing relapse of secondary pain after 48-72 h post surgery. Therefore, care should be taken when studying new chemical entities targeted for central nervous system in jugular vein cannulated rats and in general interpretation of PK results for all studied compounds. Care should be taken to ensure that the catheter does not get blocked after surgery and patency should be checked at least once a day. In addition, the personnel have to ensure that the cannula does not come out during the experimental phase, putting the study in jeopardy.

For saphenous vein sampling, the sampling area is shaved and petroleum jelly or silicone oil is applied on the site of sampling to avoid spreading of blood sample. A capillary tube of capacity 50$100 \mu \mathrm{L}$ coated with anticoagulant is used for sampling, ruling out any coagulation related issues.

Using the three sampling techniques, clearance, volume of distribution and half-life of Dapsone were similar and compared well with the published data. This showed that primary PK parameters were not affected by sampling site. Bioavailability was high and similar in all the groups again confirming no differences due to sampling site. Although we used very well characterized dapsone for assessing the sampling site effect, more compounds needs to be assessed to build a robust data base.

\section{Conclusion}

All blood sampling techniques employed are invasive and cause at least some stress and pain if used without suitable anesthesia. The present work compared different sampling techniques like orbital sinus, jugular vein and saphenous vein for determining the PK parameters of dapsone following different intravenous and oral administration. The PK parameters of dapsone were found to be statistically insignificant in spite of using different sampling techniques. Compared to assessed sampling techniques, we found saphenous vein sampling to have the following advantages. For saphenous vein sampling, animals are not catheterized, blood volume drawn can be controlled without hemolysis of samples and no upfront preparation is required to initiate the study at short notice. The only drawback during saphenous vein sampling is the animal handling which may lead to stress. In addition, saphenous vein sampling can be extended to mouse which would not only decrease the animals used in sparse sampling design but would also help to compare the inter-animal variability in PK parameters. Toxicokinetic studies which are typically long term, JVC rats are not preferred as the animals may be prone to infection, cannula may get blocked or cannula may come out during the study.Use of saphenous vein sampling would reduce the number of animals in TK group and at the same time give more robust TK parameters as the samples will be drawn from the same animal. Authors recommended 
saphenous vein sampling to be the most appropriate from scientific and ethical perspective for conducting PK and TK studies in rodents. To summarize, SV sampling reduce the number of animals in different PK (mouse) and TK (mouse and rat) studies by using serial draws, offers refinement over the other sampling techniques with minimal preparation upfront and with a potential to replace them.

\section{Acknowledgments}

Rao Mukkavilli would like to thank Advinus Therapeutics and Manipal University for giving an opportunity to work for doctoral research.

\section{References}

1. Sarlis NJ. Chronic blood sampling techniques in stress experiments in the rats: a mini review. AnimTechnol. 1991; 42: 51-9.

2. Diehl KH, Hull R, Morton D, Pfister R, Rabemampianina Y, Smith D, et al. A good practice guide to the administration of substances and removal of blood, including routes and volumes. J Appl Toxicol. 2001; 21(1): 15-23.

3. Verbaeys A, Ringoir S, Van Maele G, Lameire N. Influence of feeding, blood sampling method and type of anesthesia on renal function parameters in the normal laboratory rat. Urol Res. 1995; 22(6): 377 82.

4. Lee C, Sarna SK. Central regulation of gastric emptying of solid nutrients meals by corticotropin releasing factor. Neurogastroenterol Motil. 1997; 9(4): 221-9.

5. Molpeceresa J, Chacona M, Bergesa L, Pedraz LJ, Guzmán M, Aberturas MR. Age and sex dependent pharmacokinetics of cyclosporine in the rat after a single intravenous dose. Int J Pharmacol. 1998; 174: 9-18.

6. Van Herck H, Baumans V, Brandt CJ, Boere HA, Hesp AP, van Lith HA, et al. Blood sampling from the retro-orbital plexus, the saphenous vein and the tail vein in rats: comparative effects on selected behavioral and blood variables. Lab Anim. 2001; 35(2): 131-9.

7. Hem A, Smith AJ, Solberg P. Saphenous vein puncture for blood sampling of the mouse, rat, hamster, gerbil, guinea pig, ferret and mink. Lab Anim. 1998; 32: 364-8.

8. Thrivikraman KV, Huot RL, Plotsky PM. Jugular vein catheterization for repeated blood sampling in the unrestrained conscious rat. Brain Res Protoc. 2002; 10(2): 84-94.

9. Peternel L, Skrajanar S, Cerne M. Comparative study of four permanent cannulation procedures in rats. J Pharmacol and Toxicol Methods. 2010; 61(1): 20-6.

10. Cocchetto DM, Bjornsson TD. Methods for vascular access and collection of body fluids from the laboratory rat. J Pharm Sci. 1983; 72(5): 465-92.

11.Zeller W, Weber H, Panoussis B, Bürge T, Bergmann R. Refinement of blood sampling from the sublingual vein of rats. Lab Anim. 1998; 32: 369-76.

12. Abatan OI, Welch KB, NemzekJA. Evaluation of saphenous venipuncture and modified tail-clip blood collection in mice. J Am Assoc Lab Anim Sci. 2008; 47(3): 8-15.

13. Parasuraman S, Raveendran R, Kesavan R. Blood sample collection in small laboratory animals. J Pharmacol and Pharmacother. 2010; 1(2): 87-93.

14. Morton DB, Abbot D, Barclay R, Close BS, Ewbank R, Gask, D, et al. Removal of blood from laboratory mammals and birds. Lab Anim. 1993; 27(1): 1-22.

15. Li F, Ploch S, Fast D, Michael S. Perforated dried blood spot accurate microsampling: the concept and its applications in toxicokinetic sample collection. J Mass Spectrom. 2012; 47(5): 655-67.

16. McGee MA, Maronpot RR. Harderian gland dacryoadenitis in rats resulting from orbital bleeding. Lab Anim Sci. 1979; 29(5): 639-41.

17. van Herck H, Baumans V, Brandt CJ, Hesp AP, Sturkenboom JH, van Lith HA, et al. Orbital sinus blood sampling in rats as performed by different animal technicians: The influence of technique and expertise. Lab Anim. 1998; 32(4): 377-86.

18. van Herck H, Baumans V, Stafeu FR, Beynen AC. A questionnairebased inventory of the orbital puncture method in the Netherlands. Scandinavian J Lab Anim Sci. 1992; 19: 189-96.

19. Van Herck H, Baumans V, Van der Craats NR, Hesp AP, Meijer GW, Van Tintelen G, et al. Histological changes in the orbital region of rats after orbital puncture. Lab Anim. 1991; 26(1): 53-8.

20.Beynen AC, Van Tintelen G, Baumans V. Orbital puncture may not influence open field behavior in rats. $\mathrm{Z}$ Versuchstierkd. 1988;31(3):121-3.

21. Shirasaki Y, Ito Y, Kikuchi M, Imamura Y, Hayashi T. Validation studies on blood collection from the jugular vein of conscious mice. J Am Assoc Lab Anim Sci. 2012; 51(3): 345-51.

22. Aasland KE, Skjerve E, Smith AJ. Quality of blood samples from the saphenous vein compared with the tail vein during multiple blood sampling of mice. Lab Anim. 2010; 44(1): 25-9.

23. Curtin LI, Grakowsky JA, Suarez M, Thompson AC, DiPirro JM, Martin $\mathrm{LB}$, et al. Evaluation of buprenorphine in a postoperative pain model in rats. Comp Med. 2009; 59(1): 60-71.

24. Helton DR, Osborne DW, Pierson SK, Buonarati MH, Bethem RA. Pharmacokinetic profiles in rats after intravenous, oral or dermal administration of dapsone. Drug Metab Dispos. 2000; 28(8): 925-9.

25. Coleman MD. Dapsone: Modes of action, toxicity and possible strategies for increasing patient tolerance. Br J Dermatol. 1993; 129(5): 507-13.

26. Hui YH, Huang NH, Ebbert L, Bina H, Chiang A, Maples C, et al. Pharmacokinetic comparisons of tail-bleeding with cannula or retro-orbital bleeding techniques in rats using six marketed drugs. J Pharmacol Toxicol Methods. 2007; 56(2): 256-64.

27. Rees RS, Altenbern DP, Lynch JB, King LE Jr. Brown recluse spider bites. A comparison of early surgical excision versus dapsone and delayed surgical excision. Ann Surg. 1985; 202(5): 659-63.

28. Davies B, Morris T. Physiological parameters in Laboratory Animals and Humans. Pharm Res. 1993; 10(7): 1093-95. 